\title{
MODELLING AND EVALUATION OF MULTI-VECTOR ENERGY NETWORKS IN SMART CITIES
}

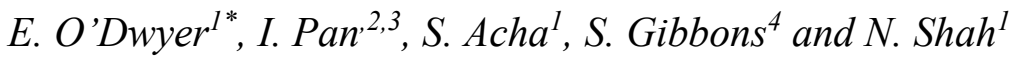 \\ ${ }^{1}$ Department of Chemical Engineering, Imperial College London, London SW7 2AZ, UK \\ ${ }^{2}$ The Alan Turing Institute, The British Library, London NW1 2DB, UK \\ ${ }^{3}$ Centre for Environmental Policy, Imperial College London, London SW7 2AZ, UK \\ ${ }^{4}$ The Greater London Authority, London SE1 2AA, UK \\ * Corresponding author
}

\begin{abstract}
Energy demand growth and the rapid rate of technological change in an urban context are already having an impact on our energy systems. Considering global ambitions to reduce carbon emissions and minimise the rate and impacts of climate change, this demand will need to be met with energy from low carbon sources. Increased electrification of heat and transport networks is anticipated, however, the crosssectoral impacts of different interventions in these systems must be better understood to prevent gains in one system leading to losses in another while ensuring financial benefits for producers and consumers. As such, evaluating the impacts of specific interventions can be a challenge, with analyses typically focussed on individual systems. In this paper, a simulation environment is developed to capture the behaviour of interconnected heat, power and transport networks in an urban environment to act as a 'digital twin' for the energy systems of a district or city. The modelling environment illustrated here is based on the smart city interventions in Greenwich (London), with model validation carried out using real data measurements. Building retrofit and heat electrification interventions are demonstrated in terms of costs, energy consumption and $\mathrm{CO} 2$ emissions, considering constraints on power and thermal systems.
\end{abstract}

\section{Introduction}

Globally, cities are responsible for $60 \%$ of present day GHG emissions and waste (United Nations), accounting for $67-76 \%$ of energy use (Edenhofer et al., 2014). Furthermore, current projections indicate that approximately $66 \%$ of the world's population will be urban by 2050 , growing from $54 \%$ in 2014 (United Nations Department of Economic and Social Affairs Population Division, 2014). Significant efforts are needed to reduce the environmental impact of cities across all sectors, with the energy sector playing a key role. The above statistics speak to the scale of the challenges ahead, however, the high energy densities and diverse demand profiles also provide opportunities for technological innovation (Lund et al., 2014; Zhou et al., 2016).

Within the wider 'Smart City' context, the concept of 'Smart' energy has gathered momentum in recent years, with digital communication technology and computational intelligence providing the means to increase the integration and coordination of lower carbon energy sources (O'Dwyer, 2019). While the benefits of integrated energy networks have been widely reported (Mancarella, 2014; Shah and Keirstead, 2013), assessing the impact of individual interventions on the whole system can be a challenge. Suitable choices of technologies and operating strategies are contingent on quantified benefits (economic, environmental or otherwise) across all energy vectors. With increased electrification of heating and transport for example, a large-scale building retrofit may not only reduce heating requirements, but also reduce the peak electrical load of the system, which in turn may enable a greater grid capacity to be available for additional loads, such as electric vehicle charge-points. Evaluating the impact across all systems may be crucial to the selection of appropriate technology and the development of strong business cases. Predicting the multi-vector behaviour of the system requires a modelling platform that can capture the interactions of heating, transport and local generation networks.

A wide range of modelling tools are currently available to decision makers. A summary of suitable tools for modelling renewable energy integration is provided in (Connolly et al., 2010) for example, while approaches for modelling districtscale energy systems are reviewed in (Allegrini et al., 2015) with a further classification of energy system models provided in (Hall and Buckley, 2016). Suitable modelling approaches depend on several factors, including desired time-scale (seconds to decades), technology and hierarchy level (e.g. country-wide, district-level or component level). Design decisions and operational decisions also require different modelling approaches. As the electrification of heating and transport systems becomes more prevalent, the interactions between different system components increases. From a modelling perspective, a challenge then arises, in that a modelling platform must capture the interactions while maintaining the level of detail required to simulate the behaviour of the individual components. The effective simulation of building energy demand for example, requires dynamic modelling tools such as EnergyPlus (DOE, 2017) to 
accurately capture heat transfer through building fabric. District level simulation tools tend to simulate operation only for a given set of energy demands however (Connolly et al., 2010), and often neglect lower level components.

Building on work carried out for the EU Horizon 2020 funded Sharing Cities project (http://www.sharingcities.eu), this paper details the development of a modelling framework that can capture both the detailed thermal dynamics and the technological diversity present in a district level smart energy system and illustrates its efficacy through application to the real Smart City environment of Greenwich. The platform, referred to henceforth as the "digital twin" of the real system, consists of various modelled components (both thermal and electrical) including local photovoltaic solar generation, electric vehicle charge stations and a large social housing unit along with its associated heating network, which includes boilers, water source heat pumps and thermal storage. Furthermore, the digital twin incorporates the Sustainable Energy Management System (SEMS) developed for the Sharing Cities project, which enacts a set of advanced control algorithms to enable optimal operation of the various interacting sub-systems. All components are simulated within the same co-simulation environment incorporating interactions between systems. The platform is designed to be transferable to any urban energy management context using only open-source software. This ability to scale to different scenarios taking into consideration both high-level system constraints and low-level physical constraints, while capturing the interactions between the different subsystems makes it a novel and relevant framework for design, analysis and evaluation.

The paper first provides an overview of the Greenwich energy systems considered here. Following this, the software architecture of the digital twin is illustrated. The validity of the twin is then established by comparing the simulated outputs with measured data taken from the real systems, showing a high degree of accuracy across several months of data. Following this, a set of case studies are carried out to investigate the impacts of different Smart City-type interventions in the system. More specifically, the interconnected impacts of building retrofit, heat electrification and renewable generation are quantified in terms of economic and environmental and factors.

\section{Smart energy landscape - Greenwich}

As one of three lead cities in the Sharing Cities project, a wide range of interventions are underway in London, specifically focussed in the borough of Greenwich. These interventions include increasing the electrification of heat and transport networks, implementing additional renewable generation and retrofitting part of the social housing stock. The multi-vector nature of the interventions makes Greenwich a suitable case study for the developed simulation platform framework. The interventions captured in the modelled case study are summarised in this section.

\subsection{Energy system assets}

The Ernest Dence estate (shown in Figure 1) is located near the south bank of the River Thames in Greenwich. Consisting of the 95 apartments, ranging in size from 2-5 bedroom, the estate is used for social housing by the Royal Borough of Greenwich (RBG). Space heating is provided by gas boilers, with an average annual gas consumption (measured between 2009 and 2013) of approximately $2 \mathrm{TWh}$, which amounts to $370 \mathrm{kWh} / \mathrm{m}^{2}$. This greatly exceeds the average figures for the UK (Department for Business Energy \& Industrial Strategy, 2018). To reduce the energy consumption and the reliance on gas, a retrofit is to be carried out. Roof insulation is to be improved while the network of piping associated with the heating system is to be redesigned to reduce heat losses.

\section{Figure 1: The Ernest Dence estate (Greenwich, UK) (image taken from Map data @2019 Google)}

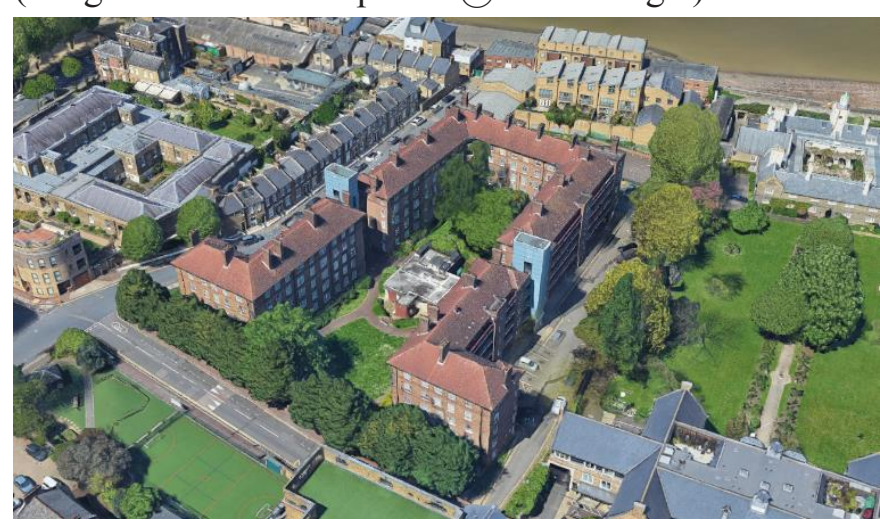

Water source heat pumps (WSHP) with a combined capacity of $400 \mathrm{~kW}$ are to be used to supply heat to the estate using the Thames as the heat source while the heating system operating temperature is to be lowered, necessitating a redesign of the buildings radiators. Lower temperatures ensure more efficient WSHP operation as well as reduced heat loss from the pipes. Water tanks with a total capacity of $6 \mathrm{~m}^{3}$ will also be available for thermal storage, while additional boilers will be used only when required as a back-up heat source.

Aside from the Ernest Dence estate, solar PV panels are to be installed on the roofs of several other social housing blocks in the Greenwich area with a combined capacity of $270 \mathrm{kWp}$. Furthermore, a shift in transport in the Borough towards greater penetration of electric vehicles will be facilitated by the installation of EV charge stations.

\subsection{Sustainable energy management system}

The applications of the previously outlined interventions differ, with transport, heating and generation all represented, however, the presence of heat network supplied by an electrically powered heat pump indicates that the systems can be seen to interact through the power network. These interactions must be considered at the district level. If peaks in the power drawn by the EV charge stations coincide with peaks in the heating requirement for example, the local electricity grid may become over-stressed. On the other hand, the flexibility provided by the heating network through the 
presence of thermal storage (including the water tanks as well as the storage associated with the large thermal mass of the apartment block itself) allows for temporal shifting of the electrical loads. With appropriate management, coinciding peaks can then be avoided. Furthermore, variable energy prices and grid carbon intensities can be exploited to minimise energy use at times of high price or high $\mathrm{CO}_{2}$ intensity, or maximise the local use of power generated through renewables. To handle these considerations, a Sustainable Energy Management System (SEMS) has been developed for the Sharing Cities project.

To succeed as a tool for design, analysis and evaluation, a digital twin of the energy landscape must be able to incorporate all outlined system components within a single platform, capturing interactions between components while allowing advanced control and optimisation-based strategies to be simulated.

\section{Simulation environment - the digital twin}

\subsection{Architecture of digital twin and SEMS}

To handle the range of potential energy components within a single framework in an open-source manner while allowing for co-simulation with different modelling software, the Building Controls Virtual Test Bed (BCVTB) (Simulationresearch, 2016) in the Ptolemy II framework (Eker et al., 2003) was chosen as the central modelling environment. The actororiented design of Ptolemy II allows different components to execute concurrently, suiting the modular nature of a multiscale energy system, while BCVTB enables coupling with other software packages. Furthermore, the platform can be allowed to communicate with an external set of control algorithms through a web application framework. A high-level schematic of the information flow between different software components is illustrated in Figure 2. By simulating all sensor measurements present in the proposed real system, it should be possible to design the control algorithms using the digital twin and simply swap out the twin for the real system after enough testing and analysis has been carried out, though control aspects are not the focus of this paper.

Figure 2: Information flow chart of the digital twin

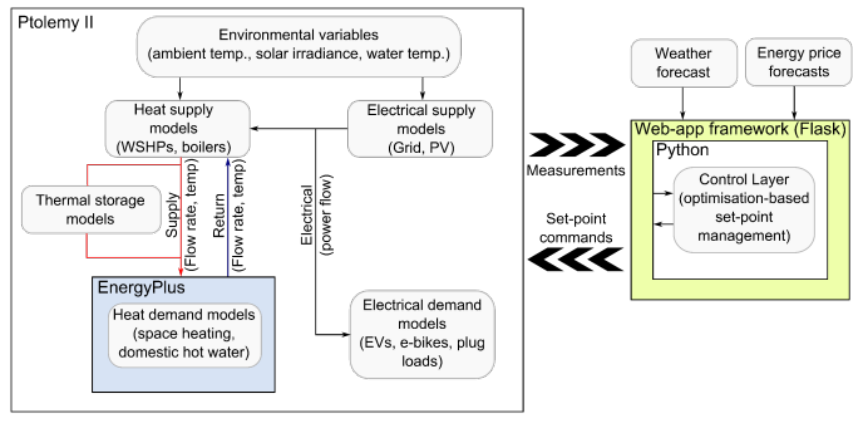

\subsection{Modelling Greenwich systems}

In the Greenwich case, the digital twin is composed of a heating network (with boilers, heat pumps and thermal storage), the apartment block it supplies, EV charge stations and PV panels. External temperatures, solar irradiance profiles, energy prices and EV charger loads are included as time-series actors. The heat pumps, boilers, thermal stores and low-level controllers and valves are modelled by standard heat transfer and mass balance equations, implemented using standard Ptolemy mathematical actors, logic blocks and lookup tables. The thermal dynamics of the apartments are modelled using the state-of-the-art building modelling software EnergyPlus (Crawley et al., 2000). Taking work initially carried out in the MOEEBIUS project (www.moeebius.eu/), the dimensions, materials and radiator system design of the Ernest Dence estate are used to develop a high-fidelity model in EnergyPlus. A graphical representation of the physical model is shown in Figure 3.

Figure 3: Representation of the modelled Ernest Dence residential estate

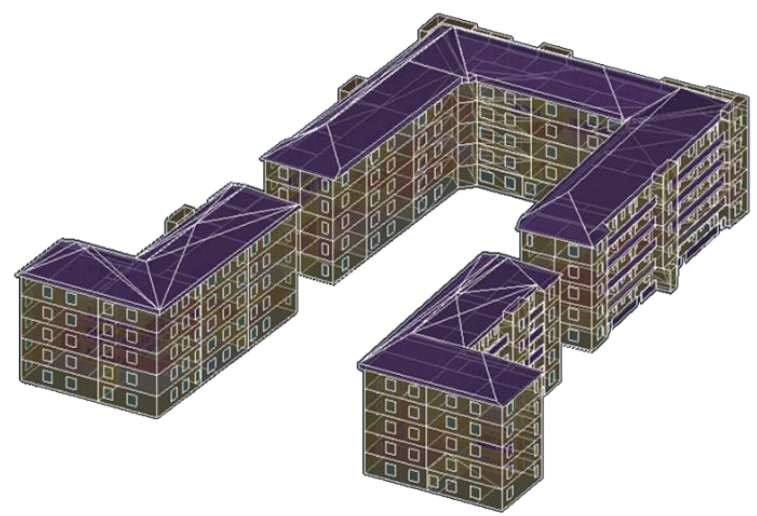

Heating system supply temperatures and system set-points are passed from the Ptolemy-based heating system model to the EnergyPlus model, while room temperatures and system return temperatures are passed back. The top level of the digital twin graphical user interface is shown in Figure 4.

Figure 4: Digital twin top-level user-interface schematic

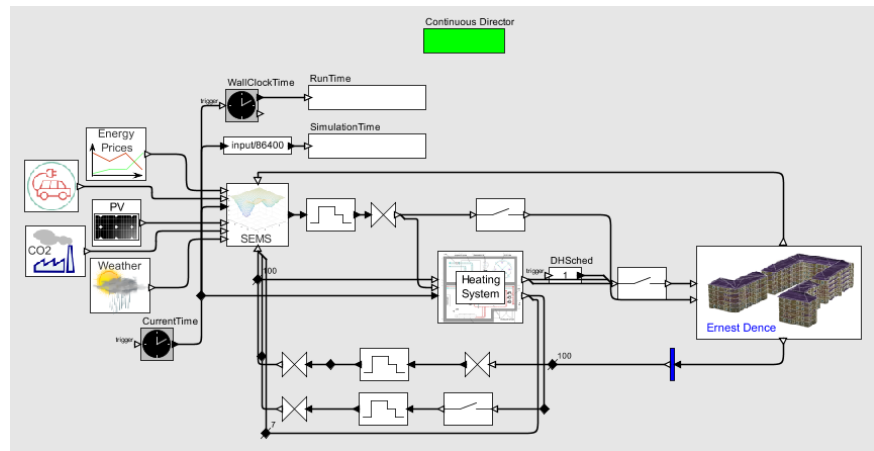

All sensors planned for the real system are present in the digital twin with measurements passed to the control layer via a web application framework (Flask, 2014). The python-based control layer calculates an optimal set of operational set-points which are then passed back to the digital twin at a chosen sample time (15-minute samples are typically used here).

\subsection{Validation of model accuracy}

As previously stated, one of the key advantages of having a simulation environment is the ability to analyse different 
scenarios prior to implementation in the real world. As such, it can be a challenge to validate the accuracy of the modelled components with real data, given that the real-world components may not yet exist. While this is true in the case of most of the energy system components in this Greenwich case (such as the heat pump), perhaps the key component - the Ernest Dence estate itself - does exist, though in pre-retrofit form. Half-hourly gas consumption measurements are available for the full estate, which allows a comparison to be made between the digital twin and the real system. Using the pre-retrofit building and heating system parameters (with only boilers as the heat source) a 50-day simulation was run to emulate the period from the 09/02/2018-30/03/2018 using weather data for the same period taken from (timeanddate.com). The external hourly temperature profile for the period is shown in Figure 5. It should be noted that no cooling exists in the building and only the thermal loads have been considered here.

Figure 5: External hourly temperature in London during the modelled period

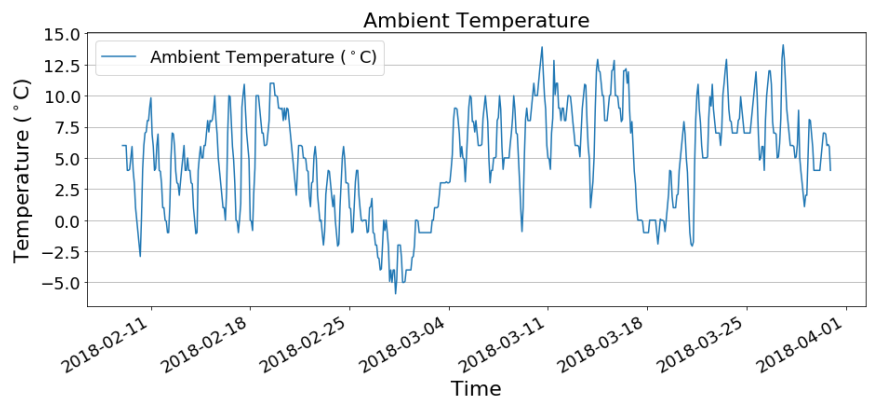

Simple assumptions were required to generate occupancy profiles and internal radiator set-points as this level of data was not available. Inevitably, differences will arise between any such assumptions and the reality of the hour-to-hour and dayto-day lives of the residents, particularly relating to how they interact with radiators and windows. Nonetheless, broadly assuming an averaging-out over time of such differences, it should be possible to observe the relationship between the external conditions and the energy consumption. To see this, the gas consumption predicted by the digital twin is compared here to the actual gas consumption as measured in the estate for the full 50-day period. This is shown in Figure 6 where the solid line indicates the measured data, while the dashed line indicates the consumption predicted by the model.

Figure 6: Metered vs modelled heat demand of the Ernest Dence estate

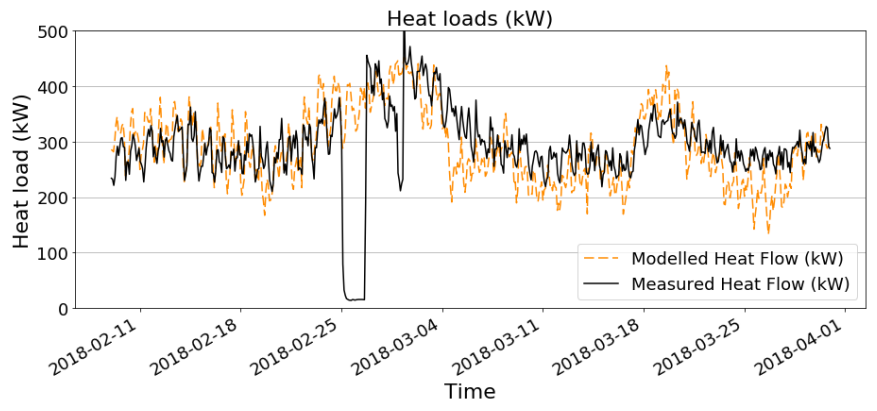

A 40-hour period during which an apparent fault in the real data measurements can be seen, starting on the 25/02/2018. Apart from this, the heating profiles show strong similarities in terms of both the seasonal and daily variations, with the expected inverse relationship to the external temperature clearly visible in both. Removing the data-points associated with the 40-hour fault period from both profiles, the total gas consumption is shown for the remaining measured and modelled data in Table 1. The heat underestimation of $3.1 \%$ compares favourably with other high-fidelity building simulation studies (Glasgo, 2017).

Table 1: Metered vs. modelled total gas consumption for the 50-day period in Ernest Dence estate over unfaulted period

\begin{tabular}{cccc}
\hline & $\begin{array}{c}\text { Measured } \\
(\mathrm{MWh})\end{array}$ & $\begin{array}{c}\text { Modelled } \\
(\mathrm{MWh})\end{array}$ & $\begin{array}{c}\text { Difference } \\
(\%)\end{array}$ \\
\hline $\begin{array}{c}\text { Total gas } \\
\text { consumption }\end{array}$ & 346.7 & 335.8 & 3.1 \\
\hline
\end{tabular}

Criteria for a more rigorous assessment of building simulation performance can be found in (ASHRAE, 2002), with two key metrics applied here. The Normalised Mean Bias Error (NMBE) is used to indicate the average deviation of the predicted values from the measured values in the form of a percentage. For $N$ samples, where measurements are denoted $y$, modelled predictions are denoted $\hat{y}$, and the mean of the measured samples is denoted $\bar{y}$, the NMBE is given as:

$N M B E=\frac{100}{\bar{y}} \frac{\sum_{i=1}^{N}\left(y_{i}-\hat{y}_{i}\right)}{N}$

As the NMBE can be prone to cancellation errors (Ruiz and Bandera, 2017), assessment can be complemented by the inclusion of the Coefficient of Variation of the Root Mean Square Error (CV(RMSE)), which provides an indication of the load shape (Granderson et al., 2015). With the same notation as Equation (1), this is given as:

$C V(R M S E)=\frac{100}{\bar{y}} \sqrt{\frac{\sum_{i=1}^{N}\left(y_{i}-\hat{y}_{i}\right)^{2}}{N}}$

These criteria were applied to hourly values from the same data-set, with the outcome compared to the ASHRAE guideline 14 values shown in Table 2 . The model performance falls well inside the bounds suggested in the guidelines for both indicators.

Table 2: NMBE and CV(RMSE) for modelled data compared to ASHRAE standards

\begin{tabular}{lcc}
\hline & $\begin{array}{c}\text { Simulation } \\
\text { Accuracy }\end{array}$ & $\begin{array}{c}\text { ASHRAE } \\
\text { guideline 14 }\end{array}$ \\
\hline NMBE & $3.2 \%$ & $\pm 10 \%$ \\
CV(RMSE) & $17.5 \%$ & $30 \%$ \\
\hline
\end{tabular}




\section{Evaluating interventions}

\subsection{Building retrofit - Gas boilers}

To improve the energy performance of the estate, a retrofit is to be carried out by the council, in which the roof loft insulation is to be increased. Currently, $150 \mathrm{~mm}$ depth insulation is present. This shall be increased $300 \mathrm{~mm}$ to achieve a U-value of $0.13 \mathrm{~W} / \mathrm{m}^{2}$ or better. To simulate this, the parameters associated with the roof insulation were modified appropriately in the EnergyPlus model.

The radiator pipework and heat network are also to be redesigned and reinstalled to reduce heat losses to the environment and to unheated zones in the estate. The length of the pipework is to be significantly reduced through better routing, while improving the insulation of the pipework and reducing the pipe diameter should all lead to reductions in unwanted heat transfer from the pipes. Once again, the relevant parameters in the model were modified and the digital twin was run for the same 50-day period once again. The energy consumption predicted by the model before and after the retrofit interventions is shown in Figure 7 where the solid line represents the modelled heat load before retrofit, while the dashed line represents the heat after the retrofit.

Figure 7: Modelled energy consumption before and after retrofit activities

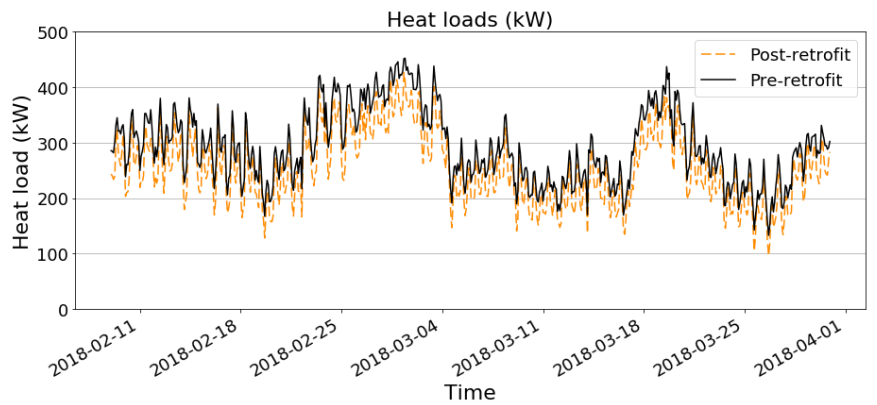

The resulting impact of the retrofit is evaluated in terms of $\mathrm{CO}_{2}$ emission and fuel cost in Table 3. It was assumed that the gas boilers operated at $78 \%$ efficiency (the boilers are quite old), while a gas cost of $18.3 \mathrm{c} / \mathrm{kWh}$ is used. A value of 0.184 $\mathrm{kgCO}_{2} / \mathrm{kWh}$ is assumed for the $\mathrm{CO}_{2}$ intensity of natural gas, taken from (Department for Business Energy and Industrial Strategy, 2018). With these data, an energy consumption reduction of $12.8 \%$ is predicted in the 50-day simulation period after retrofit interventions have taken place. This corresponds to a decrease in fuel costs of more than $£ 1000$, with a reduction in $\mathrm{CO}_{2}$ emissions of more than $10 \mathrm{tCO}_{2}$. While these values are taken for a 50-day period during one of the coldest periods of the year, longer simulations can be carried out to obtain results spanning years if needed. Alternatively, annualised energy costs can be inferred from the short-term results using simple assumptions (e.g. assuming the \% change is consistent throughout the year). From a decision-maker's perspective (in this case, local government), the capital costs of the interventions, both in terms of money and $\mathrm{CO}_{2}$, can be weighed against these quantified operational benefits, enabling more informed decisions to be made about the worthiness of any retrofit interventions.

Table 3: Predicted gas consumption for 50-day period in Ernest Dence residential estate before and after retrofit interventions

Pre-retrofit Post-retrofit

\begin{tabular}{lcc}
\hline Gas Consumption $(\mathrm{MWh})$ & 449.4 & 391.9 \\
$\mathrm{CO}_{2}$ emission $(\mathrm{t})$ & 82.7 & 72.1 \\
Fuel cost $(\mathfrak{f})$ & 8,224 & 7,172 \\
\hline
\end{tabular}

\subsection{Impact of heat electrification in district - Water source heat pumps}

Given the reduction in $\mathrm{CO}_{2}$ intensity of the UK's electricity grid in recent years (HM Government, 2017) and the potential to exploit high Coefficients of Performance (COPs), the environmental impact of the heating sector can be greatly reduced by shifting the burden of heating from gas boilers to electrically driven heat pumps. With this in mind, a further intervention to be implemented in Greenwich is the installation of a water source heat pump to replace the current aging centralised boiler system in the Ernest Dence estate. A hybrid system is to be established in which four heat pumps with a combined capacity of approximately $400 \mathrm{kWth}$ (depending on the source temperature) are to be used, with an additional set of boilers to be installed as a backup, for use when the energy demand exceeds the installed heat pump capacity. A lower heat network temperature set-point of $60{ }^{\circ} \mathrm{C}$ is to be used to ensure that a favourable heat pump COP is achieved. This will require the installation of larger radiators in the apartments to allow for adequate heat transfer between the radiators and the air, given the reduced temperature difference between the two. Two thermal stores of $3 \mathrm{~m}^{3}$ each are also to be installed as a buffer.

The new system components were modelled in the digital twin with a simulation run carried out once again for the 50-day period. The COP of the water source heat pump is assumed to reduce from 3.5 to 2 as the source (the river) temperature decreases from $20^{\circ} \mathrm{C}$ to $4{ }^{\circ} \mathrm{C}$ (based on monthly average river temperatures measured at Littlebrook Power Station). A simple on/off hysteresis-type strategy is used to control the output of the heat pump. If the return temperature of the heat network falls to more than $2{ }^{\circ} \mathrm{C}$ below its set-point, the heat pumps switch on until the network temperature rises back above the set-point, at which point they switch off again. In times where the heat pump capacity is insufficient, the network temperature will continue to drop, in which case the back-up boilers switch on as a supplementary supply.

Using this operational logic, the performance of the gas boiler system is compared to that of the proposed heat pump (in both cases it is assumed that the previously described insulation and pipework retrofit interventions have already taken place). A two-tier electricity tariff is assumed for the apartments, with a day tariff of $10.7 \mathrm{p} / \mathrm{kWh}$ and a night tariff of $6.6 \mathrm{p} / \mathrm{kWh}$. The 
$\mathrm{CO}_{2}$ intensity of the electricity grid for the period is taken from the National Grid's Carbon Intensity API (Carbon Intensity API) which provides half-hourly values. The resulting performance is summarised in Table 4. In the heat pump-based system, the gas boilers are used infrequently and as such, the gas consumption is greatly reduced. The shift towards electricity introduces a significant decrease in $\mathrm{CO}_{2}$ emission ( $63 \%)$, however the cost of supplying the energy has increased by about $9 \%$. Despite the significant reduction in energy consumption, the relatively high day tariff makes the heat pump more expensive to run when compared with the gas boilers in this case. From this, the operational cost of $\mathrm{CO}_{2}$ mitigation can be taken as $15.64 £ / \mathrm{tCO}_{2}$.

Table 4: Operational impact of heat electrification

\begin{tabular}{lcc}
\hline & $\begin{array}{c}\text { Pre- } \\
\text { electrification }\end{array}$ & $\begin{array}{c}\text { Post- } \\
\text { electrification }\end{array}$ \\
\hline Gas (MWh) & 391.9 & 8.1 \\
Electricity (MWh) & 0 & 81.0 \\
$\mathrm{CO}_{2}$ emission $(\mathrm{t})$ & 72.1 & 26.8 \\
Energy cost $(£)$ & 7,172 & 7,881 \\
\hline
\end{tabular}

To reduce costs, an alternative strategy can be implemented in which the heat pumps are only run during the night, with the boilers used during the day. Furthermore, the thermal stores can be optimally managed using the SEMS control framework to ensure cost is minimised. This is achieved by charging during the night period using the heat pump and discharging during the day to maximise the exploitation of the heat pumps during the low-tariff periods. The performance of this approach is summarised in Table 5. Here, the cost is approximately the same the boiler-based system, with a reduction in $\mathrm{CO}_{2}$ of $25 \%$.

Table 5: Performance of combined WSHP/Boiler strategy

\begin{tabular}{lcc}
\hline & $\begin{array}{c}\text { Pre- } \\
\text { electrification }\end{array}$ & $\begin{array}{c}\text { Post- } \\
\text { electrification }\end{array}$ \\
\hline Gas (MWh) & 391.9 & 197.7 \\
Electricity (MWh) & 0 & 25.9 \\
$\mathrm{CO}_{2}$ emission $(\mathrm{t})$ & 72.1 & 53.8 \\
Energy cost $(£)$ & 7,172 & 7,158 \\
\hline
\end{tabular}

The three different strategies are illustrated in Figure 8 in terms of $\mathrm{CO}_{2}$ emissions and energy cost. This case is illustrative of the type of trade-off that can commonly be found in the energy sector as competing financial and environmental objectives can produce opposing design decisions, while operational strategies must also be considered. The choice of the 'best' strategy can be subjective. With the use of the digital twin, different strategies can be evaluated quantitively to assist the decision-maker.
Figure 8: Environmental and financial comparison of operational strategies

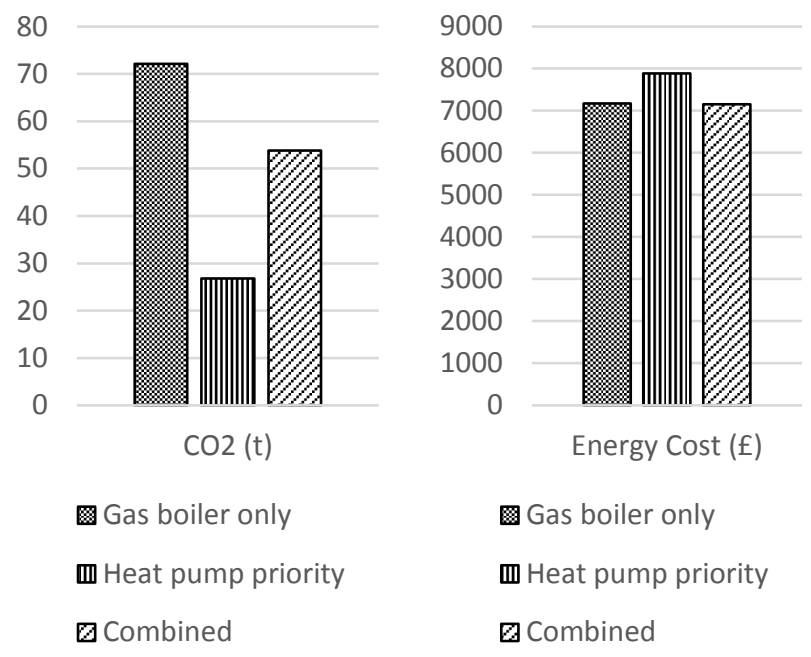

\subsection{Impact of renewable PV installation in district}

As previously indicated, the borough also seeks to increase the renewable generation in Greenwich through the installation of PV panels. Considering the greater electrical requirement resulting from heat pump-based heating systems, this is a critical initiative. The PV panels are modelled here using standard algebraic blocks from the Ptolemy library. As such, the models of the PV devices can be directly implemented in the digital twin, without the need for further simulation packages to be included. Following the approach described in (Duffie and Beckman, 2013), the ratio of the intensity of solar radiation on a surface of a given orientation and tilt angle to that of a horizontal surface can be calculated based on the time of day, time of year, orientation and latitude. Using this, along with the horizontal-surface irradiances taken from (EnergyPlus, 2016), the intensity of solar radiation on each $\mathrm{m}^{2}$ of each PV panel is calculated and converted to a generated power value using the specified conversion efficiency from the PV panel manufacturers.

Using the heat pump prioritised strategy from Section 4.2, the electrical generation and consumption of the new assets in Greenwich is plotted in Figure 9 for the same 50-day simulation period. Consumption is plotted as positive, while generation is plotted as negative.

Figure 9: Electricity consumption and generation in new assets

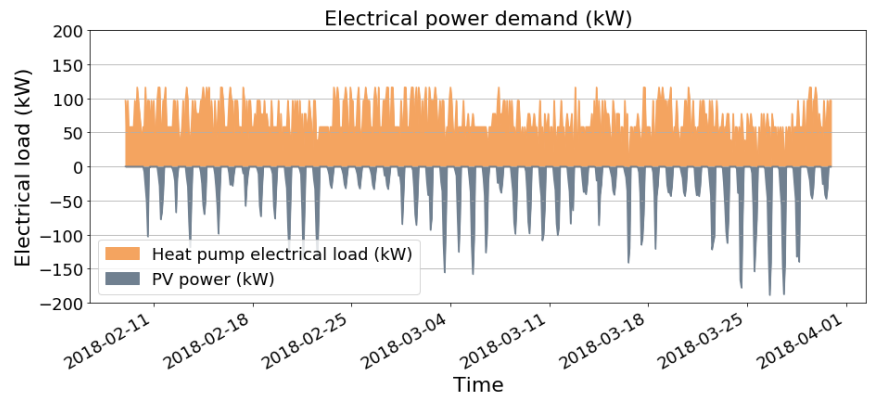


The offset cost and $\mathrm{CO}_{2}$ achieved using the PV panels is summarised in Table 6 . With $270 \mathrm{kWp}$ of installed capacity, the generation of approximately $24.9 \mathrm{MWh}$ electricity was predicted for the 50-day period. With the assumption that the produced power can be consumed locally, this can reduce the electricity import cost by over $£ 2600$. Taking all interventions into account, the $\mathrm{CO}_{2}$ emission from the modelled assets in the borough can thus be reduced from $83 \mathrm{t} / \mathrm{CO}_{2}$ to $19 \mathrm{t} / \mathrm{CO}_{2}$ for the simulated period. This equates to a reduction of $77 \%$.

Table 6: Operational impact of PV installation

\begin{tabular}{lcc}
\hline & $\begin{array}{c}\text { Pre- } \\
\text { interventions }\end{array}$ & $\begin{array}{c}\text { Post- } \\
\text { interventions }\end{array}$ \\
\hline PV generation $(\mathrm{MWh})$ & 0 & 24.9 \\
Offset energy cost $(£)$ & 0 & 2636 \\
Offset $\mathrm{CO}_{2}(\mathrm{t})$ & 0 & 7.8 \\
Total $\mathrm{CO}_{2}(\mathrm{t})$ & 82.7 & 19.0 \\
Total energy cost $(\mathfrak{})$ & 8,224 & 5,245 \\
\hline
\end{tabular}

\section{Conclusion}

As smart city interventions become more common in the urban energy landscape, reliable methods for analysing and evaluating the system-wide impacts of any action is required. Energy networks are becoming more interlinked with the electrification of the heating and transport sectors. Decision makers require transferable tools with the flexibility to be used in different contexts to enable the impacts of design or operational decisions to be quantified. In this paper, a modelling platform, or digital twin, is proposed to capture the interactions between various urban energy systems while incorporating enough detail to rigorously evaluate specific interventions in terms of operational costs and $\mathrm{CO}_{2}$ emission. The proposed software architecture is first illustrated, with an emphasis on the modular open-source nature of the platform to promote transferability. To demonstrate the use of the platform, the energy systems of the borough of Greenwich are modelled. Model validation is carried out using measured data over a 50-day period. Interventions associated with the H2020 Sharing Cities project that are currently underway in the borough are then outlined, including building retrofit, the transition of a heating network supply from gas boilers to water source heat pumps and the installation of PV panels. An evaluation of these interventions is carried out using the digital twin in terms of the impact on the operational $\mathrm{CO}_{2}$ emissions and energy costs. The predicted outcomes of these interventions emphasise the need for both design and operational decisions to be considered in the evaluation process, highlighting the value of the proposed platform.

\section{Acknowledgements}

This project has received funding from the European Union's Horizon 2020 research and innovation programme under Grant Agreement No. 691895. The authors would also like to thank Siemens, the Greater London Authority and the Royal
Borough of Greenwich with whom collaboration on the project has been carried out. IP would also like to acknowledge the Imperial College Research Fellowship scheme for supporting him.

\section{References}

Allegrini, J. et al., 2015. A review of modelling approaches and tools for the simulation of district-scale energy systems. Renewable and Sustainable Energy Reviews. 52, 1391-1404.

ASHRAE, 2002. ASHRAE Guideline 14: Measurement of Energy and Demand Savings, American Society of Heating, Ventilating, and Air Conditioning.

Carbon Intensity API, URL http://carbonintensity.org.uk/ (accessed 1.7.19).

Connolly, D. et al., 2010. A review of computer tools for analysing the integration of renewable energy into various energy systems. Applied Energy 87, 1059-1082.

Crawley, D.B. et al., 2000. EnergyPlus: Energy simulation program. ASHRAE Journal 42, 49-56.

Department for Business Energy \& Industrial Strategy, 2018. National Energy Efficiency Data-Framework: Summary of analysis using the National Energy Efficiency Data Framework (NEED).

Department for Business Energy and Industrial Strategy, 2018. Greenhouse gas reporting: conversion factors 2018.

DOE, 2017. EnergyPlus | EnergyPlus. U.S. Department of Energy. URL https://www.energyplus.net/ (accessed 5.10.18).

Duffie, J.A., Beckman, W.A., 2013. Solar Engineering of Thermal Processes, John Wiley \& Sons, Inc., Hoboken, NJ, USA

Edenhofer, O. et al. 2014: Technical Summary, Climate Change 2014: Mitigation of Climate Change. Contribution of Working Group III to the Fifth Assessment Report of the Intergovernmental Panel on Climate Change. Cambridge University Press, Cambridge.

Eker, J. et al., 2003. Taming heterogeneity - The ptolemy approach. Proceedings of the IEEE 91, 127-143.

EnergyPlus, 2016. Weather Data - EnergyPlus. US Deparment Energy. URL https://energyplus.net/weather (accessed 3.19.19).

Flask, 2014. Welcome | Flask (A Python Microframework). URL http://flask.pocoo.org/ (accessed 5.13.18).

Granderson, J. et al., 2015. Assessment of Automated Measurement and Verification (M\&V) Methods, Lawrence Berkeley National Laboratory: Berkeley, CA, USA, 2015.

Hall, L.M.H., Buckley, A.R., 2016. A review of energy systems models in the UK: Prevalent usage and categorisation. Applied Energy 169, 607-628.

HM Government, 2017. The Clean Growth Strategy: Leading the way to a low carbon future. BEIS 165 .

Lund, H. et al., 2014. 4th Generation District Heating (4GDH). Integrating smart thermal grids into future sustainable energy systems. Energy 68, 1-11. 
Mancarella, P., 2014. MES (multi-energy systems): An overview of concepts and evaluation models. Energy 65, 1-17. MOEEBIUS, URL http://www.moeebius.eu/ (accessed 5.10.18).

Ruiz, G.R., Bandera, C.F., 2017. Validation of calibrated energy models: Common errors. Energies 10.

Shah, N., Keirstead, J., 2013. Urban Energy Systems: An Integrated Approach. Routledge, Oxford.

SHARING CITIES, URL http://www.sharingcities.eu/ (accessed 5.13.18).

Simulationresearch, 2016. FrontPage - bcvtb, URL https://simulationresearch.lbl.gov/bcvtb (accessed 5.13.18).

timeanddate.com, URL https://www.timeanddate.com/ (accessed 1.3.19).

UN, Global Initiative for Resource Efficient Cities, Paris, France. United Nations Environ. Program. URL https://resourceefficientcities.org/ (accessed 12.19.18).

United Nations Department of Economic and Social Affairs Population Division, 2014. World Urbanization Prospects.

Zhou, K. et al., 2016. Big data driven smart energy management: From big data to big insights. Renewable and Sustainable Energy Reviews 56, 215-225. 